Original article

\title{
Association between Homesickness and the Related Factors with Happiness in the Dormitory Students of Hamadan University of Medical Sciences, Iran
}

\author{
Babak Moeini ${ }^{1}$, Hamid Abbasi ${ }^{2}$, Maryam Afshari ${ }^{2 *}$, Morteza Haji Hosseini ${ }^{3}$, Soheila Rashidi \\ 1. Associate Professor of Health Education, Social Determinants of Health Research Center, \\ Hamedan University of Medical Sciences, Hamedan, Iran \\ 2. PhD Candidate in Health Education and Promotion, Student Research Center, Hamedan \\ University of Medical Sciences, Hamedan, Iran \\ 3. MSc in Biostatistics, Center for Atherosclerosis and Coronary Artery Research, Birjand \\ University of Medical Sciences, Birjand, Iran \\ 4. MSc Student in Health Education, Student Research Center, Hamedan University of Medical \\ Sciences, Hamedan, Iran
}

\begin{abstract}
Background and objectives: Admission to university is an important event in the life of youth in every country. Homesickness is one of the most significant issues faced by university students during their education life. The present study aimed to determine the association between homesickness, happiness and the related factors in the dormitory students in Hamadan University of Medical Sciences, Iran.

Methods: This cross-sectional, descriptive-analytical study was conducted on 387 dormitory students at Hamedan University of Medical Sciences in Hamedan, Iran during February-March 2015. Subjects were selected via stratified random sampling with proportional allocation. Data were collected using self-report and using demographic and contextual questionnaires, Fenfelit homesickness questionnaire, and oxford happiness questionnaire. Data analysis was performed in SPSS version 23 using Pearson's correlation-coefficient and general linear model (GLM) at the significance level of 0.05 .

Results: The mean score of homesickness in both genders had a significant difference $(\mathrm{P}=0.009)$. In addition, the mean score of happiness differed in terms of economic status. Homesickness was negatively correlated with the happiness score, so that increased homesickness was associated with reduced happiness. Variables of homesickness, age, internet use, maternal education, health status, economic status, and education level could significantly predict happiness.
\end{abstract}

Conclusion: Mental health of students in dormitories is of paramount importance. Therefore, interventions and preventive programs must recognize the causes of happiness, and appropriate interventions should be developed and implemented based on the influential factors in this regard.

Keywords: Mental health, Homesickness, Happiness, Dormitory, Student

Corresponding Author: Maryam Afshari

Address: Student Research Center, Hamedan University of Medical Sciences, Hamedan, Iran

E-mail: afshari.m@umsha.ac.ir 


\section{Introduction}

Mental health is one of the foremost health indices of a community (1). In every community, people are exposed to multiple psychiatric disorders (2). University students are faced with an intense period in their education life which could be associated with more different problems than the other community members (3). Due to changing their place of residence and sudden separation from their families, students are at a higher risk of mental health issues comparatively (4). During the studying period, all students, especially medical students, face challenges such as living in a student dormitory and assessment by professors. Other specific issues for medical students include mental and emotional stress in the hospital environment, emergency rooms, health centers, dealing with patients, and length of education. Therefore, medical students are at a higher risk of deteriorated mental health with variable degrees compared to other students (5).

Some researchers believe that experiencing mental issues diminishes the sense of happiness; in other words, when individuals constantly deal with problems, their happiness is likely to decrease, threatening their mental health (6). Depression is one of the main consequences of homesickness, which affects the quality of life of students and reduces their happiness in their living environment (7). In a research by Khoshkonesh et al., a negative significant correlation was reported between the depression and happiness of students (8).

One of the most important challenges faced by students during their education is the sense of homesickness. Homesickness is a complex cognitive, motivational, and emotional state which is associated with mental preoccupations with the former environment and tendency to returning to that environment. Homesick individuals often experience depressive moods and various mental symptoms (9). Homesickness may lead to lack of reliable relations and loneliness, predisposing the individual to anxiety, depression, drug and alcohol addiction and even suicide (10). Considering the value of happiness and its impact on life, especially during university education, identification of the influential factors in happiness is of paramount importance. Identifying these factors enables individuals to achieve happiness and prevent many psychological issues, such as depression. The present study aimed to determine the associations between homesickness and the related factors to the happiness of students in the dormitories of Hamedan University of Medical Sciences in Hamedan, Iran in 2015.

\section{Materials and Methods}

This cross-sectional, descriptive-analytical research was conducted on 387 students living in the dormitories of Hamedan University of Medical Sciences during February-March 2015. Subjects were selected via random stratified sampling with proportional allocation. The total population size in this research was 1,968 students living in the dormitories of the university. Since no similar research had been conducted in this regard, the correlation-coefficient of homesickness and mental health was estimated at 0.43 using the study by Roudbordeh et al. (11). The minimum total number of the students was calculated at 53 based on the following equation, where $\alpha=0.05, \quad \beta=0.1$, and $r$ represents the correlation-coefficient between two quantitative variables. However, based on similar studies, 400 students were selected as the final participants. 


$$
n=\frac{\left(Z_{1-\alpha}+Z_{1-\beta}\right)^{2}}{\left(\frac{1}{2} \ln \frac{(1+r)}{(1-r)}\right)^{2}}+3
$$

Considering the number of students residing in the university-covered dormitories, the sample size of the study was determined in each dormitory using proportional allocation. The residential dormitories with a higher number of students were assigned a larger sample size. It is notable that the university has five dormitories for female students and two dormitories for male students. Inclusion criteria of the study were studying at Hamedan University of Medical Sciences and residing in the governmental dormitories of the university.

Data were collected using two selfreporting questionnaires, which were completed by the participants after obtaining written informed consent. Demographic characteristics included age, gender, field of study, semester, education level, school/faculty, marital status, place of residence, number of siblings, birth order, economic status, health status, parental education level, parental occupation status, level of physical activities, reading nonacademic books and daily use of television, internet and computer games. The demographic questionnaire was completed by the students at the beginning of the evaluation process. The homesickness questionnaire was designed by Fenfelit in 2001. This scale consisted of 45 items with five factors, including 'missing the family' (items 1-11), 'desire to return home' (items 12-20), 'homeliness' (items 21-26), 'incompatibility with new environments' (items 27-33), and 'missing close friends' (items 34-36). In a sample size of 349 subjects, the Cronbach's alpha coefficient for the abovementioned factors was estimated at 0.90, 87.85, 0.0, 0.88 and 0.80 , respectively, which demonstrated the high internal consistency of the questionnaire. Moreover, the questionnaire consisted three supplementary evaluations; the first two items (number 46 and 47) assessed the frequency of homesickness in the current situation and the past, respectively, and the last item (number 48) evaluated the severity of homesickness. Ejei et al. evaluated the psychometric properties of this questionnaire in 2008. Findings of the mentioned study confirmed the internal consistency among the factors of the questionnaire (12). Items in the homesickness questionnaire were scored within a range of 15 (Never, Low, Moderate, High and Extremely High, respectively). Total score of homesickness was obtained by achieving the sum of the scores obtained in each item. The minimum and maximum scores were 36 and 180, respectively, where the high scores demonstrated the high level of homesickness, and the low scores indicated the low level of homesickness in the participants. In order to evaluate the condition of the subjects in terms of the research factors, the raw scores of the items in each factor were added up.

Another data collection tool in the present study was Oxford happiness questionnaire, which consisted of 29 items to assess the level of happiness in the participants. The theoretical basis of this questionnaire was the definition of happiness by Crossland and Argyle; accordingly, happiness is a structure with three main sections including the frequency and degree of positive affection, mean satisfaction level during a specific period and lack of negative feelings. Oxford happiness questionnaire was designed by Argyle in 1989 based on Beck's depression inventory (BDI) (13). In total, the items in BDI $(n=21)$ were reversed and used in this questionnaire, along with 11 other items to cover the other aspects of mental health. Similar to BDI, Oxford happiness questionnaire has four alternatives, and the subjects should choose one of the options in 
accordance with their current situation. Argyle et al. have calculated the reliability and retest reliability of Oxford happiness questionnaire at the Cronbach's alpha of 0.90 and 0.78 over seven weeks, respectively. The concurrent validity of the questionnaire has been estimated at 0.43 by assessing the views of the friends of the participants (13). Furthermore, the validity of Oxford happiness questionnaire has been confirmed by Alipoor and Noorbala (14). Oxford happiness questionnaire has 29 multiple-choice items, where the alternatives $\mathrm{A}, \mathrm{B}, \mathrm{C}$, and $\mathrm{D}$ represent the scores of zero, one, two and three, respectively. The minimum and maximum scores of the scale are zero (dissatisfaction with life/depression) and 87 (the highest level of happiness), respectively. The normal score of the test is within the range of 40-42.

Data analysis was performed in SPSS version 23 using descriptive statistics (mean and standard deviation), Pearson's correlation-coefficient, and general linear model (GLM) at the significance level of 0.05. Moreover, the Kolmogorov-Smirnov test was applied to assess the normal distribution of the variables, and Levene's test was used to determine the homogeneity of the variances. Independent samples t-test and one-way analysis of variance (ANOVA) were used to compare the mean values. Tukey's post-hoc test was also employed for the paired comparison of the variables.

\section{Results}

In total, 387 students participated in the research, and $97 \%$ of the questionnaires were filled. Mean age of the students was $22.2 \pm 0.1$ years $(23.0 \pm 0.2$ years in males and $21.7 \pm 0.2$ years in females). In terms of education level, the majority of the participants had a bachelor's degree $(n=261 ; 67.4 \%)$. In addition, 93 students (25\%) were studying in the second semester, and the fathers of 79 subjects $(20.4 \%)$ had primary education.
Mothers of 312 participants (80.6\%) were housewives, and 226 subjects (58.4\%) had no physical activity.

According to the information in Table 1, there was a significant difference between the male and female students in terms of the mean score of homesickness $(P=0.009)$. Mean score of homesickness in the female participants was higher than the male participants. Moreover, results were indicative of different happiness scores in the students with various economic statuses. The results of Tukey's post-hoc test showed a significant difference in the mean score of happiness in the subjects with excellent economic status and those with good/poor economic status $(P=0.001)$. In other words, the students with a better economic status received higher scores in happiness. Furthermore, the results indicated a difference in the mean scores of happiness and homesickness in the students regarding health status. Accordingly, the subjects with proper health status received significantly higher scores in happiness compared to the other research groups, with the exception of the subjects with poor health status $(P=0.001)$. A significant difference was also observed in the score of homesickness between the study group with poor health status and other research groups, with the exception of the subjects with relatively good health status. On the other hand, no significant difference was observed in the mean scores of happiness and homesickness in terms of the education level and number of siblings $(P>0.05)$. Regarding maternal education level, the mean score of homesickness was different in the group with deceased mothers, mothers with associate degree and $\mathrm{PhD}$ education levels. Furthermore, the mean score of homesickness had a significant difference in the students whose mothers had a PhD compared to those whose mothers had a master's degree or primary education, as well as those with 
illiterate mothers $(P=0.028)$. A statistically significant difference was denoted in the mean score of homesickness between the students whose fathers were deceased and those with unemployed fathers $(P=0.045)$. In addition, there was a significant difference in the mean score of happiness between the students who used internet for one hour compared to those who used internet for three, four, and five hours per day $(P=0.030)$.

Table 1. Comparison of Mean Scores of Homesickness and Happiness Based on Demographic Characteristics

\begin{tabular}{|c|c|c|c|c|c|}
\hline \multirow{2}{*}{ Variables } & \multirow{2}{*}{ Group } & Happiness & \multirow{2}{*}{ P-value } & Homesickness & \multirow{2}{*}{$\begin{array}{c}\text { P- } \\
\text { value }\end{array}$} \\
\hline & & $\operatorname{Mean} \pm$ SD & & Mean \pm SD & \\
\hline \multirow{2}{*}{ Gender } & Male & $38.6 \pm 1.0$ & \multirow{2}{*}{0.069} & $101.1 \pm 1.7$ & \multirow[b]{2}{*}{0.009} \\
\hline & Female & $41.0 \pm 0.8$ & & $107.3 \pm 1.5$ & \\
\hline \multirow{4}{*}{$\begin{array}{c}\text { Economic } \\
\text { Status }\end{array}$} & Excellent & $51.3 \pm 3.5$ & \multirow{4}{*}{$<0.001$} & $105.6 \pm 6.2$ & \multirow{4}{*}{0.854} \\
\hline & Good & $40.9 \pm 1.0$ & & $106.2 \pm 1.8$ & \\
\hline & Moderate & $39.1 \pm 0.8$ & & $104 \pm 1.5$ & \\
\hline & Poor & $32.0 \pm 2.8$ & & $104.8 \pm 4.5$ & \\
\hline \multirow{5}{*}{$\begin{array}{l}\text { Health } \\
\text { Status }\end{array}$} & Good & $43.4 \pm 0.7$ & \multirow{5}{*}{$<0.001$} & $102.9 \pm 1.5$ & \multirow{5}{*}{0.022} \\
\hline & Relatively Good & $35.6 \pm 1.2$ & & $109.2 \pm 2.2$ & \\
\hline & Moderate & $36.6 \pm 1.6$ & & $105.2 \pm 3.1$ & \\
\hline & Relatively Poor & $26.1 \pm 5.6$ & & $98.5 \pm 5.0$ & \\
\hline & Poor & $34 \pm 12.4$ & & $136.6 \pm 14.4$ & \\
\hline \multirow{5}{*}{$\begin{array}{c}\text { Maternal } \\
\text { Education } \\
\text { Level }\end{array}$} & Deceased & $43.2 \pm 3.8$ & \multirow{5}{*}{0.161} & $90.5 \pm 5$ & \multirow{5}{*}{0.028} \\
\hline & Illiterate & $38.2 \pm 1.5$ & & $103.2 \pm 2.4$ & \\
\hline & Below Diploma & $37.8 \pm 1$ & & $101 \pm 1$ & \\
\hline & Diploma & $42.5 \pm 1.5$ & & $105.8 \pm 2.5$ & \\
\hline & Academic Degree & $41.5 \pm 1.1$ & & $105.8 \pm 1$ & \\
\hline \multirow{6}{*}{$\begin{array}{l}\text { Paternal } \\
\text { Occupation } \\
\text { Status }\end{array}$} & Deceased & $46.7 \pm 1.0$ & \multirow{6}{*}{0.116} & $94.6 \pm 4.6$ & \multirow{6}{*}{0.045} \\
\hline & Employed & $40.2 \pm 1$ & & $106.2 \pm 2.2$ & \\
\hline & Self-employed & $39.6 \pm 1.0$ & & $106.1 \pm 1.6$ & \\
\hline & Retired & $40.6 \pm 1.6$ & & $98.6 \pm 3.2$ & \\
\hline & Farmer & $37.6 \pm 1.9$ & & $109.2 \pm 3.5$ & \\
\hline & Unemployed & $35.2 \pm 11.6$ & & $115.5 \pm 23.1$ & \\
\hline \multirow{6}{*}{$\begin{array}{c}\text { Daily } \\
\text { Internet } \\
\text { Use (hour) }\end{array}$} & 1 & $44.8 \pm 2.0$ & \multirow{6}{*}{0.030} & $106.3 \pm 3.5$ & \multirow{6}{*}{0.353} \\
\hline & 2 & $41.8 \pm 1.5$ & & $99.6 \pm 2.9$ & \\
\hline & 3 & $38 \pm 1.3$ & & $107.3 \pm 2.5$ & \\
\hline & 4 & $39.2 \pm 1.3$ & & $102.6 \pm 2.3$ & \\
\hline & 5 & $38.8 \pm 1.2$ & & $106.7 \pm 2.1$ & \\
\hline & None & $41.6 \pm 3.5$ & & $105.5 \pm 5.8$ & \\
\hline
\end{tabular}


According to the information in Table 2, homesickness had a reverse correlation with the score of happiness $(-0.2)$, so that the increased sense of homesickness reduced the happiness of students $(\mathrm{P}=0.001)$.

Table 2. Pearson's Correlation-Coefficient of Happiness and Homesickness

\begin{tabular}{|c|c|c|}
\hline Variables & Happiness & Homesickness \\
\hline Happiness & 1 & \\
\hline Homesickness & -0.2 & 1 \\
\hline
\end{tabular}

According to the results of the study, the mean scores of happiness and homesickness were $40.1 \pm 0.6$ and $105 \pm 1.1$, respectively. According to the information in Table 3, the mean scores of various dimensions in the homesickness questionnaire were $39.3 \pm 0.4$, $24.8 \pm 0.4,14 \pm 0.2,16.8 \pm 0.3$, and $9.9 \pm 0.1$ for 'missing the family', 'desire to return home', 'loneliness', 'incompatibility with new environments', and 'missing close friends', respectively.
Table 3. Mean Scores of Dimensions in Homesickness Questionnaire

\begin{tabular}{|c|c|}
\hline Dimensions & Mean \pm SD \\
\hline Missing Family & $39.0 \pm 3.4$ \\
\hline Desire to Return Home & $24.0 \pm 8.4$ \\
\hline Loneliness & $0 \pm 14.2$ \\
\hline $\begin{array}{c}\text { Incompatibility with } \\
\text { New Environments }\end{array}$ & $16.0 \pm 8.3$ \\
\hline Missing Close Friends & $9.0 \pm 9.1$ \\
\hline
\end{tabular}

According to the information in Table 4, there were direct, significant correlations between the dimensions of 'missing the family', 'desire to return home' (0.4), and 'missing close friends' (0.4). In addition, direct, significant associations were observed between the dimensions of 'desire to return home', 'loneliness' (0.4), 'incompatibility with new environments' (0.4), and 'missing close friends' (0.3). Direct, significant correlations were also denoted between the dimensions of 'loneliness', 'incompatibility with new environments' (0.6), and 'missing close friends' (0.2), as well as the dimensions of 'missing close friends' (0.2) and 'incompatibility with new environments' $(0.2)$.

Table 4. Pearson's Correlation-Coefficient of Various Dimensions in Homesickness Questionnaire

\begin{tabular}{|c|c|c|c|c|c|}
\hline Dimensions & $\begin{array}{l}\text { Missing } \\
\text { Family }\end{array}$ & $\begin{array}{c}\text { Desire to } \\
\text { Return Home }\end{array}$ & Loneliness & $\begin{array}{c}\text { Incompatibility with } \\
\text { New Environments }\end{array}$ & $\begin{array}{l}\text { Missing Close } \\
\text { Friends }\end{array}$ \\
\hline Missing Family & 1 & & & & \\
\hline $\begin{array}{c}\text { Desire to Return } \\
\text { Home }\end{array}$ & $\begin{array}{c}0.4 \\
<0.001\end{array}$ & 1 & & & \\
\hline Loneliness & $\begin{array}{c}0.01 \\
0.824\end{array}$ & $\begin{array}{c}0.4 \\
<0.001\end{array}$ & 1 & & \\
\hline $\begin{array}{c}\text { Incompatibility } \\
\text { with New } \\
\text { Environments }\end{array}$ & $\begin{array}{c}0.07 \\
0.132\end{array}$ & $\begin{array}{c}0.4 \\
<0.001\end{array}$ & $\begin{array}{c}0.6 \\
<0.001\end{array}$ & 1 & \\
\hline $\begin{array}{l}\text { Missing Close } \\
\text { Friends }\end{array}$ & $\begin{array}{c}0.4 \\
<0.001\end{array}$ & $\begin{array}{c}0.3 \\
<0.001\end{array}$ & $\begin{array}{c}0.2 \\
<0.001\end{array}$ & $\begin{array}{c}0.2 \\
<0.001\end{array}$ & 1 \\
\hline
\end{tabular}


The results of univariate GLM are presented in Table 5. Accordingly, the variables of homesickness, age, internet use, maternal education level, health status, education grade, and economic status could significantly predict the happiness of the students.

\section{Discussion}

Today, moving has become an integral part of daily lives with specific outcomes, including homesickness. Various studies have reported homesickness in the students in different communities and cultures. According to the results of the present study, a moderate level of homesickness was observed in the students residing in the dormitories of Hamedan University of Medical Sciences (Iran), which is in accordance with the results obtained by Khademi and Farashi Aghdam and Terry et al. $(15,16)$. Other studies in different regions of Iran have denoted homesickness in students, especially those who were far from their home $(12,17)$. According to the current research, the homesickness of the students was mostly due to missing their family, followed by other dimensions of homesickness. In the study by Ejei et al. (2008), the sense of homesickness, was observed in the majority of students, particularly in the dimension of 'missing the family', (12).

One of the aims of the current research was to assess the associations between the score of homesickness and demographic characteristics of the students residing in dormitories. While the sense of homesickness was observed in both genders, it was higher in the females compared to the males. Conflicting results have been proposed in this regard, and our findings are in congruence with the results obtained by Strobe et al. (2002) and Besharat et al. (2006). These researchers reported a higher score of homesickness in women compared to men $(18,19)$. Our findings are inconsistent with the results obtained by Downs (2002) (20). Therefore, it could be inferred that depression is an important component of homesickness, which is more prevalent among women than men. In addition, women tend to express their emotional issues more frequently than men. In contrast to women, men need more social connectivity and are able to find a new social network more easily than a woman, which in turn reduces their sense of homesickness.

Another finding of the present study was the reverse correlation between homesickness and health status of the students, which is in line with the previous studies $(21,22)$. Moreover, a significant association was denoted between homesickness and maternal education level, so that the students whose mothers had higher educational degrees experienced a lower level of homesickness. This shows that educated mothers better understand and socially support (emotional support and evaluation) their children, which positively affects the feelings of children and helps them overcome this feeling after moving away from home $(11,23)$.

According to the results of the present study, paternal occupation status influenced the homesickness of the students, so that the participants whose fathers had better jobs experienced a lower level of homesickness. This might be due to the contentment with the economic status of the family and no concern about the life conditions of one's family members.

In general, the students residing in the dormitories of Hamedan University of Medical Sciences had a normal happiness status. This might be due to the small area of the dormitories, which contributes to the intimacy of students. In addition, these dormitories have created favorable environments for the students in terms of facilities. Moreover, the majority of the 
students were from the neighboring provinces and cities of Hamedan; therefore, they could return home easily, and the convenience affected their happiness.

Another aim of the current research was to evaluate the correlation between homesickness and happiness in the students residing in the dormitories of Hamedan University of Medical Sciences. According to the results, there was a reverse, significant association between homesickness and score of happiness in the participants, so that increased homesickness reduced happiness. In this respect, Anasori reported a direct, significant correlation between the mental health and happiness of the subjects (24). Therefore, it could be concluded that higher mental health increases the happiness of individuals and happiness also results in improved mental health.

In a research by Pernegar (2004), an association was observed between happiness and mental health, which is consistent with our findings. Moreover, a significant association was denoted between the health status and happiness of the subjects. According to the findings of Jayasvasti (2005), there is a positive significant correlation between increased happiness and better mental health, appetite, sleep, memory, family condition, mental health, and relations with family members and friends (26).

In the current research, proper use of the internet could predict the happiness of the students. In a study by Samouei et al., one of the leisure activities of the students residing in university dormitories was using computers and the internet. The mentioned issue shows that responding to the needs of students for joy and fun does not require complicated planning, facilities, and costs, and such responsiveness is rather easy and accessible (27).

In the present study, economic status could predict the happiness of the students, so that better economic status was associated with increased happiness. It seems that better economic status results in access to better facilities, which increases the happiness of individuals. Moreover, the education level of the students could significantly predict their happiness, so that those with higher education levels were happier than those with lower education.

Owing to their positive attitude toward their future career and economic status, individuals of higher social classes tend to be comparatively happier. In the present study, maternal education level was a significant predictive factor for the happiness of the students. It seems that mothers with higher education pay more attention to the mental state of their children and provide better care in terms of mental issues. According to the current research, authorities must focus on providing a high-quality life, especially in terms of the mental state, for the students living in university dormitories. Being far from the family, having new and different responsibilities, communicating with different cultures, and adapting to new conditions require the necessary energy and ability of students to achieve inner satisfaction and happiness.

One of the strengths of the present study was the simultaneous evaluation of happiness, homesickness, and depression, while the majority of the studies in this regard have assessed only two variables. Some of the limitations of the research were the self-report nature of the research and time of data collection.

In conclusion, our findings indicated that it is crucial to focus on the mental health of the students residing in university dormitories. The causes of homesickness must be recognized through interventional and preventive programs, and proper interventions must be planned and executed in order to prevent the unwanted and irreversible 
consequences in students. In addition, it is recommended that further investigation be conducted on happiness and the contributing factors in students so as to implement educational courses and cognitive services by experts for students upon admission to the university. Such measures could minimize the experience of homesickness in the students residing in dormitories.

\section{Acknowledgements}

This research was approved by the Ethics Committee of Hamedan University of Medical Sciences, Hamedan, Iran (code: IR.UMSHA.REC.1394.353). Hereby, we extend our gratitude to Hamedan University of Medical Sciences for the financial support of this study, which was carried out as a research project approved by the Student Research Center (code: 9409245167). We would also like to thank all the students for assisting us in this research project. 


\section{References}

1. Mohammadi MR, Davidian H, Noorbala AA, Malekafzali H, Naghavi HR, Pouretemadet HR, et al. An epidemiological survey of psychiatric disorders in Iran. Clin Pract Epidemol Ment Health $2005 ; 1: 16$.

2. Rohany Nasir Z, Zamania A, Khairudina R, Latipunb. Effects of Family Functioning, Selfesteem, and Cognitive Distortion on Depression among Malay and Indonesian. Juvenile Delinquents 2010; 10(83): 1877-0428.

3. Barron LW. Effect of religious coping skills training with group cognitive-behavioral therapy for treatment of depression: Northcentral University, College of psychology; 2007.

4. Rezaei Adaryani M. Comparison of depression, anxiety, stress and quality of life for Male and female students living in Tarbeyat Modares student dormitories. Pajoheshe Parastari 2007; 2(4): 31-38. [Persian]

5. Narimani A, Akbarzadeh $M$, Hamzeh $M$. Evaluation of general health in medical students of AJA University of medical sciences. Aja Journal. 2009; 8(1): 55-49. [Persian]

6. Alberktsen G. happiness and related factors in pregnant women, deparyment of psychiatare, faculty of mediene. Chulalongkorn University, Bangkok, Thailand, 2003.

7. Seligman, M. Authentic Happiness: Using the new positive psychology to realize your potential for lasting fulfillment. New York: Free Press, 2002.

8. Khosh Konesh A, Keshavarz Afshar H. The relationship between happiness and mental health of students. Journal of Andisheh va Raftar 2008; 2(7): 41-51. [Persian]

9. Farhadi M. Study of relationship between attachment style and homesickness. Dissertation for M.A. Tehran Univ 2005. [Persian]

10. Tavakoli Sh, Lumley Mark A, Hijaz Alaa M, Slavin-Spenny Olga M, Parris George P. Effect of assertiveness training and expressive writing of acculturative stress in international student. A randomized trial. J Counseling Psychology 2009; 56(4): 590-567.

11. Pour Agha Roudbordeh F, Kafi Seyed Mousa, Rezaei Sajad. Relationship between homesickness and perceived social support and mental health of students Newcomer. Clinical Psy \& Personality 2012; 19(6):45-66.

12. Ejei J, Dehghani M, Ganjavi A, Khodapanahi MK. Validation of Utrecht Homesickness Scale in Students. J Behavioral Sciences 2008; 2(1): 1-12. [Persian]

13. Argyle M, Crossland J. Dimensions of positive emotions. British Journal of Social Psychology 1987;26: 127-137.

14. Alipoor A, Noorbala A A. A Preliminary Evaluation of the Validity and Reliability of the Oxford Happiness Questionnaire in Students in the Universities of Tehran. IJPCP. 1999; 5 (1 and 2) :55-66

15. Khademi A, Farashi Aghdam AA. The role of persoality traits and resistance on homesickness of college student. Social and Behavioral Sciences 2013;82:537-541.

16. Terry ML, Leary MR, Mehta S. Selfcompassion as a Buffer against Homesickness,

Depression, and Dissatisfaction in the Transition to College. Self and Identity, 2012, 1-13, i First article.

17. Yaghobi A, Farhadi M, Ghanbari N, Kakabarai K. Examine the relationship between emotional intelligence and general health with homesickness. Journal of Psychology University of Tabriz. 2008; 3(9): 137-153. [Persian]

18. Strobe M, Van Vliet T, Hewstone M, Willis H. Homesickness among students in two cultures: antecedents and consequences. British Journal of Psychology, 2002;93:147-168.

19. Besharat MA, Farhadian M, Gilani B. Investigate the relationship between attachment 
style and homesickness. Journal of Psychology University of Tabriz. 2006; 1(2/3): 23-47. [Persian]

20. Downs J. Adapting to secondary and boarding school: self concept, place identify and homesickness. Driving International Research Agendas, James Cook University, Australia.2002.

21. Messina J. Helping students cope with Homesickness. University Business, 2007;116(10), 80-180.

22. Van Vliet T. Homesickness: antecedents, consequences, and mediation processes. wageningen. The Netherlands: Ponsens \& Looijen. 2001.

23. Cotrona C E. Objective determinants of perceived social support, Journal of personality and social psychology. $2007 ; 50: 349-355$.

24. Anasori M. The relationship between mental health and happiness male and female students. Andisheh va Raftar. 2007;2(6): 75-84.

25. Pernegar TV. Health and happiness in young swiss adults, Qulity of care until. Geneva university Hospital, Geneva, Switzerland. 2004.

26. Jayasvasti K. Happiness and related factors in pregnant women, deparyment of psychiatry, faculty of mediene, chulalongkorn university, Bangkok, Thailand.2005.

27. Samouei R, Moslehi M, Heydari M, Toghiani Z. Management of Students' Happiness in Dormitories of Isfahan University of Medical Sciences. Iranian Journal of Medical Education. 2012; 11(9) :1057-1062. [Persian] 
بررسى رابطه احساس غربت و عوامل مر تبط با شادكامى در دانشجويان خوابعاهى دانشعاه علوم يزشكى همدان

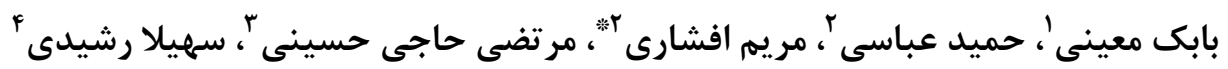

ا. ا. دانشيار آموزش بهداشت، مركز تحقيقات عوامل اجتماعى موثر بر سلامت دانشكاه علوم يزشكى همدان، همدان، ايران.

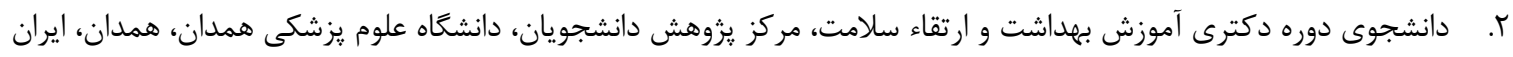

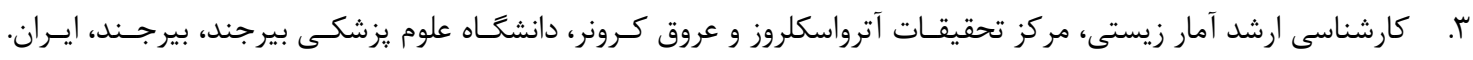

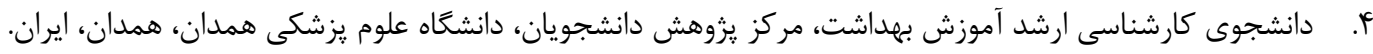

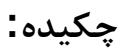

زمينه و هدف: ورود به دانشعاه يك رويداد مهم و بسيار حساس در زندگى يكى جوان در هر كشورى به شمار مى رود. يكى از مههم

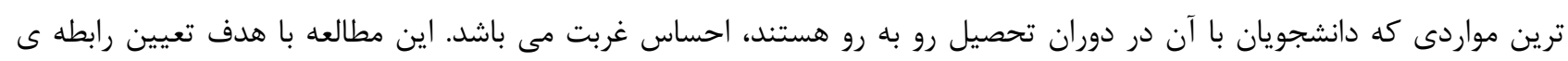

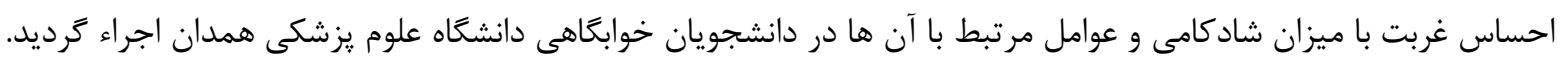

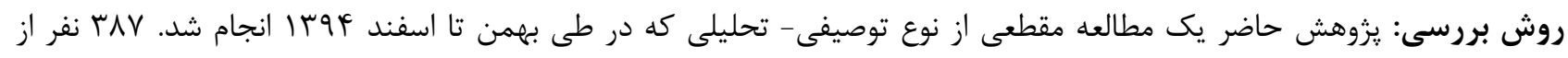

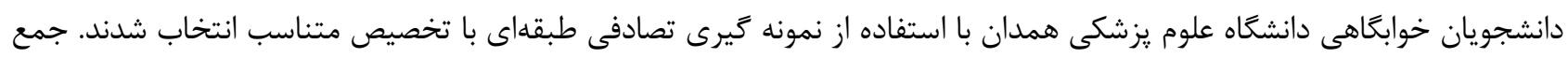

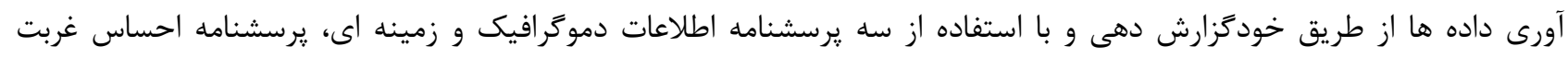

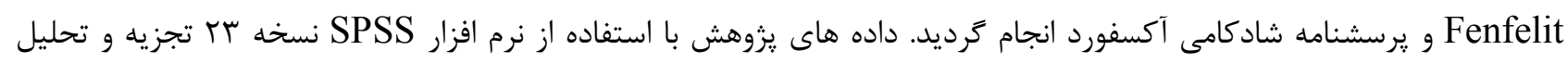

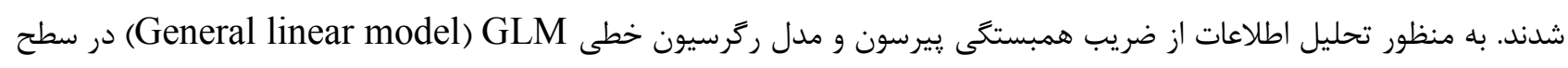
معنى دارى ه •/ • استفاده شد.

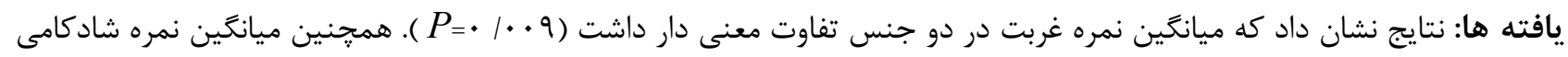

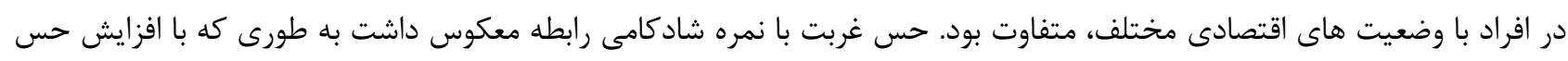

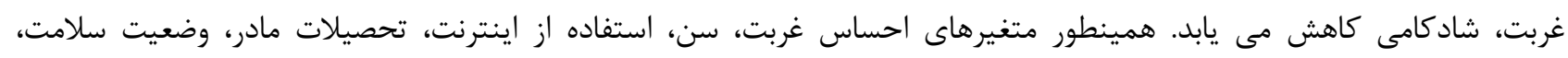
وضعيت اقتصادى و مقطع تحصيلى پيشگوهاى معنى دارى براى شادكامى هستند.

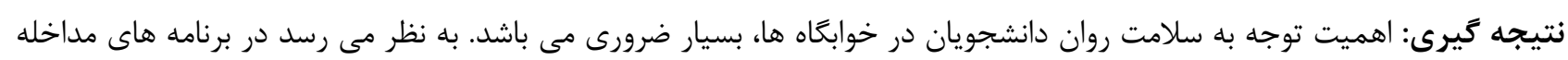

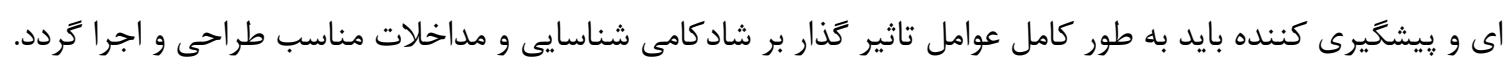
كلمات كليدى: سلامت روان، احساس غربت، شادكامى، خوابكاه، دانشجو

نويسنده مسئول: مريم افشارى

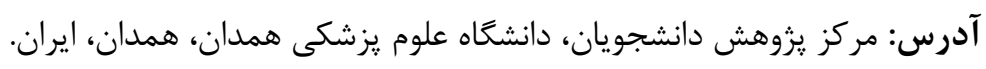
ايميل: afshari.m@umsha.ac.ir 